\title{
Collaborative Decision-Making Mechanism of Air Material Supply Based on Revenue-Sharing Contract
}

\author{
Liu Chang-xin ${ }^{1}$, Xiong Li $^{1} \&$ Li Yu-jin ${ }^{1}$ \\ ${ }^{1}$ School of Management, Shanghai University, Shanghai, China \\ Correspondence: Xiong Li, School of Management, Shanghai University, Shanghai, China, No.99, Shangda Road, \\ Bao Shan District, Shanghai, 200444, China. E-mail: xiongli8@163.com
}

Received: May 21, 2014

doi:10.5539/ijbm.v10n1p231
Accepted: December 4, 2014 Online Published: December 20, 2014

URL: http://dx.doi.org/10.5539/ijbm.v10n1p231

\begin{abstract}
Due to the complex nature of air material demand and supply process, inventory pooling among a number of airlines is an intuitive way of exploiting the scale economies of availability services, and this paper analyzes the air material supply chain within sharing model and introduces revenue-sharing contract coordination mechanism into air material supply process. On the basis of analyzing stock-out compensation and inventory costs, it establishes the coordination model of air material supply chain whose demand quantity is in accordance with Poisson Distribution and Normal Distribution. The paper presents the collaborative decision-making algorithm for air material supply chain and verifies the coordination model by means of actually analyzing a numerical example for application. Based on a reasonable contract form and contract parameters, the optimization of production and ordering quantity and expected profit of each node on the air material supply chain can be achieved and hence the optimization of collaborative decision-making of air material supply and the performance of supply chain.
\end{abstract}

Keywords: collaborative decision-making, revenue-sharing contract, supply chain optimization, air materials supply

\section{Introduction}

With the rapid development of global especially Chinese aviation industry, the limitation of the present air material management is more and more obvious. Among the operational costs of airlines, the air material reserves almost account for $75 \%$ of the inventory assets and $25 \%$ of the liquidity while in the air material life cycle, the equipment fee for repairing accounts for about $60 \%$ to $70 \%$ of the total repairing cost. The aircraft maintenance cost has always been high enough to affect the airline operational benefit so that some airlines have fallen into trouble or have to stop operating. At present, how to improve the operational efficiency and reduce the cost of air material supply based on aviation security is a critical problem for airlines to solve.

The research on how to improve the management efficiency of air material has always been focused on aspects such as the demand (Jeffery K. Cochran, et al., 2002; A. A Ghobbar, \& C. H Friend, 2002), consumption (Hugo Simao, et al., 2009), transportation and ordering storage (Lee Loo Hay, et al., 2008; Kyung Bok Yoon, So Young Sohn, 2007), etc. under the condition of certain and uncertain demand. Some cases in point are quantitative and qualitative analysis of air material supply through establishing the predictive models of material consumption (Wan Yu-Cheng, He Ya-Qun, et al., 2004; Adel A. Ghobbar, \& Chris H. Friend. 2003; A. Regattieri, M. Gamberi, et al. 2005), and seeking for collaborative approachof air material storage among airlines within different supply models(Jani Kilpi, \& Ari P. J. Vepsäläinen, 2004), the collaborative strategy model of repairable air materials using between departments of airlines and repairing companies (Jani Kilpi, Juuso Töyli, et al., 2009). But all these researches are for supply strategy only from a certain angle of supply process or a certain node in supply chain. The ordering quantity is mainly determined by the factors such as the need of aviation security department, transportation and storage costs, etc., while the most important manufacturer and repairer have not played a role in the decision-making process of air material supply. Due to the present informatization and high-integration of supply chain, the production and ordering storage cannot achieve optimal state so that a great number of air materials are wasted, hence it is urgent to establish the collaborative decision-making mechanism between aviation departments and manufacturers from the angle of collaborative management of supply chain.

The cooperation and optimization of supply chain management are mainly through introducing into supply chain 
process the mechanisms such as revenue-sharing contract(Cachon G P, Lariviere M A, 2005), quantity flexibility contract(Selcuk Karakaya, Ismail Serdar Bakal, 2013), quantity discount contract(C. L. Munson, J. Hu, 2010), sales discount contract(W. K. Wong, \& Qi \& Leung, 2009), buyback contract(Huachun Xiong, Bintong Chen, 2011) and option contract (Ningxiong Xu, Linda \& Nozick, 2009) so as to establish coordination model, optimize supply chain and thus achieve supply optimization. But because of the complexity nature of supply chain, the above coordination codes cannot achieve optimal supply chain under some constraints, so the researchers extend the coordination modes of supply chain, such as considering revenue-sharing contract (Cai Jian-hu, \& Han Yi, et al., 2011) under the condition of customer strategy choice and the out-of-stock compensation means for wait-sensitive customers(Chen Jian, \& Zhang Nan, 2008). In the air material supply process, if the ordering storage of air material suppliers is too much, there will be oversupply and the storage of the remaining air materials will lead to benefit reduction and even loss of the company. But once a certain material is out of stock, there will be accidents such as aircrafts being grounded. So the determination of proper ordering storage quantity is the critical factor of improving the performance and revenue of the entire supply chain made up of manufacturers, air material suppliers and airlines. Due to the complex nature of the changeable air material demand and supply process, this paper introduces the coordination mechanism of revenue-sharing contract into air material supply chain, extends the coordination mode, establishes the coordination models of air material supply chain for the sake of stock-out compensation and inventory costs, designs reasonable contract form and contract parameters, presents the collaborative decision-making mechanism for the optimal performance of air material supply chain to ensure the optimization of the entire state of the supply process, the production and the ordering storage of each node.

\section{Air Material Demand and Supply Mode}

The present modes of air material supply both home and abroad mainly include the supply management for self-ordering storage of airlines and military aviation sectors, the leasing management of air materials among the airlines and air material sharing management. Air material sharing refers to the supply service offered to two or more airlines by means of agreements signed by airlines capable of repairing, managing units for air material storage or air material repairers to achieve scale effect of air material supply. It is an air material supply mode developed by large airlines of Europe and America. Under the managing mode of air material sharing, the managers charge the airlines for the use of air materials according to certain algorithm agreed on in the agreements. Usually the manager of such air material is called air material pooling provider or pool. Nowadays the fee is charged internationally according to the times of aircraft taking off and landing and mainly the aircraft flight hours. Suppose the total installment time of a certain air material is $T_{1}$, the using fee per unit time is $P_{0}$, then the sharing price $P$ of the material is

$$
P=P_{0} T_{1}
$$

In the three modes of air material supply, the material demand quantity is always random and in accordance with Poisson Distribution and Normal Distribution. Suppose the material demand quantity is $X$, when $\mathrm{X} \leq 20$ and $X$ agrees with Poisson Distribution, the demand probability function $P(X)$ during the unit time $T$ is:

$$
P(X=K)=\frac{\lambda^{K}}{K !} e^{-\lambda},(\lambda>0, \mathrm{k}=0,1,2, \ldots) .
$$

When $X>20, X$ agrees with Normal Distribution, the demand probability density $f(X)$ during the unit time $T$ is:

$$
f(X)=\frac{1}{\sqrt{2 \pi} \sigma} e^{-(X-\mu)^{2} /\left(2 \sigma^{2}\right)},(\sigma, \mu \text { are constant, and } \sigma>, \mu>0,0 \leq x<+\infty) .
$$

According to the air material demand and use feature, the supply should include that of one-time consumption material and reusable turnover material with the latter accounting for only $20 \%$ of the ordering storage type in the process of air material demand but $80 \%$ of the entire storage fee. So the control of the ordering storage quantity of high-value turnover material has become the major research object in the material supply. Usually the demand quantity of most turnover material with an ordering cycle is less than 20 , so we may determine the ordering storage quantity by means of Poisson Distribution while the materials in higher demand by means of Normal Distribution to analyze the ordering storage model.

Meanwhile, compared with the production and supply of common products, the cycle of production and supply is relatively longer with more species in the process of demand and supply. Once a certain material is out of stock, it is necessary to reorder and it is quite possible not to get it in a short term, and unlike the salvage value 
of other seasonal products at the end of sales seasons, the value of the remaining materials within the relatively short ordering cycles is basically unchangeable, but if there are remaining materials during an ordering cycle, the aviation sectors must pay for the relatively high storage fee for the remaining material, but provided a certain material is out of stock, the aircraft will be grounded and the aviation sectors will suffer from huge loss. Therefore, how to determine the proper ordering storage during an ordering cycle is a critical problem in air material supply.

The main parameters are as follows:

$T$ : ordering cycle;

$T_{1}$ : the total installment time of a certain material;

$Q$ : ordering quantity;

$\omega$ : ordering unit price;

$P$ : the sharing price of a certain material;

$P_{0}$ : the sharing fee of a certain material in unit time;

$C_{S}$ : the unit operational cost of the manufacturer;

$C_{T}$ : the unit transportation cost;

$C_{0}$ : the unit operational cost of pooling provider;

$C_{I}$ : unit inventory cost (with the annual inventory rate accounting for $24 \%$ of the unit price of inventory items);

$C_{2}$ : unit stock-out cost.

\section{Decision-Making Model of Air Material Supply under the Condition of Air Material Sharing Based on Revenue-Sharing Contract}

\subsection{Coordination Model of Air Material Supply Chain under the Condition of Material Sharing}

The supply network of air material is mainly made up of units of manufacturing, supplying and using such as manufacturer, repairer, airline and pooling provider offering service to airlines. The research object within the sharing model is usually air material manufacturer, pooling provider and airline at the time of decision making for the material producing and ordering. During the material supply process, the airline and military aviation sector must pay the material storage fee and the stock-out loss when they do the managing of self-ordering storage and supply, but within the material sharing model, the storage fee and stock-out loss are paid by pooling provider. Therefore, compared with the two-level supply chain made up of manufacturer and sales company for common products, the material supply chain within the sharing model can be considered as a special two-level supply chain including material manufacturer and pooling provider. The usual coordinating model of supply chain has not been able to effectively coordinate and optimize it. The model needs extending on the basis of analyzing storage fee and stock-out compensation to be a new and optimal one for the coordination of material supply chain.

Revenue-sharing contract is actually described by the two parameters of $\omega$, the sales price of manufacturer and $\phi$, the revenue distribution proportion between the manufacturer and pooling provider. The manufacturer sells a material to the pooling provider at the sales price of $\omega$, the pooling provider will gain the benefit of $\phi(P-\omega)$ each time after the supplying service of an air material at the sharing price of $P$ and meanwhile offer the part of benefit $(1-\phi)(P-\omega)$ to the manufacturer.

Suppose the ordering quantity of pooling provider $I$ to the manufacturer $S$ is $Q, \prod_{I C}, \prod_{S C}$ respectively represent the profit of pooling provider and manufacturer, while $\prod_{T}$ the total profit of the entire supply chain(Cai Jian-hu, Han Yi, et al., 2011), and thus:

$$
\begin{aligned}
& \prod_{I C}=\phi P \min \{Q, X\}-\left(\omega+C_{0}+C_{T}\right) Q \\
& \prod_{S C}=(1-\phi) P \min \{Q, X\}+\left(\omega-C_{S}\right) Q \\
& \prod_{T}=P \min \{Q, X\}-\left(C_{S}+C_{0}+C_{T}\right) Q
\end{aligned}
$$

But when a certain piece is out of stock, the pooling provider must pay the airline a certain compensation $C_{2}$ according to agreements, but when there is oversupply for the ordered material, the pooling provider must pay the storage fee $C_{l}$ for the remaining material inventory. Therefore, it is necessary to extend the above model, include the compensation paid to the airline in the supply chain coordination and to consider the two elements of 
compensation fee $C_{2}$ and storage fee $C_{1}$ in the profit of pooling provider and the total profit of the supply chain.

Suppose the loss of pooling provider due to a certain missing piece or oversupply is $V$, and $V=|X-Q| C$, in which $C$ is constant, thus:

$$
V= \begin{cases}(X-Q) C_{2} & X>Q \\ (Q-X) \mathrm{C}_{1} & X \leq Q\end{cases}
$$

Suppose $y^{+}=\max (0, y)$, considering compensation $C_{2}$ and inventory $\cos C_{l}$, the profit of pooling provider, manufacturer and the total profit of the entire supply chain during an ordering cycle are respectively:

$$
\begin{gathered}
\prod_{I C}=\phi P \min \{Q, X\}-\left(\omega+C_{0}+C_{T}\right) Q-C_{2}(X-Q)^{+}-C_{1}(Q-X)^{+} \\
\prod_{S C}=(1-\phi) P \min \{Q, X\}+\left(\omega-C_{S}\right) Q \\
\prod_{T}=P \min \{Q, X\}-\left(C_{S}+C_{0}+C_{T}\right) Q-C_{2}(X-Q)^{+}-C_{1}(Q-X)^{+}
\end{gathered}
$$

When the demand quantity $X$ agrees with Normal Distribution, according to formula (2) and (3) (5), we can get the following expected profits respectively for pooling provider $I$, supplier $S$ and material supply chain:

$$
\begin{aligned}
\mathrm{E}\left(\prod_{I C}\right) & =\phi P E(\min \{Q, X\})-\left(\omega+C_{0}+C_{T}\right) Q-C_{2} E(X-Q)-C_{1} E(Q-X) \\
\mathrm{E}\left(\prod_{S C}\right) & =(1-\phi) P E(\min \{Q, X\})+\left(\omega-C_{S}\right) Q \\
\mathrm{E}\left(\prod_{T}\right) & =P E(\min \{Q, X\})-\left(C_{S}+C_{0}+C_{T}\right) Q-C_{2} E(X-Q)-C_{1} E(Q-X)
\end{aligned}
$$

When the demand quantity $X$ agrees with Poisson Distribution, according to formula (2) and (3) (5), we can get the following expected profits respectively for pooling provider $I$, supplier $S$ and material supply chain:

$$
\begin{aligned}
& \mathrm{E}\left(\prod_{I C}\right)=\phi P(E Q+E X)-\left(\omega+C_{0}+C_{T}\right) Q-C_{2}(E X-E Q)-C_{1}(E Q-E X) \\
& \mathrm{E}\left(\prod_{S C}\right)=(1-\phi) P(E Q+E X)+\left(\omega-C_{S}\right) Q \\
& \mathrm{E}\left(\prod_{T}\right)=P(E Q+E X)-\left(C_{S}+C_{0}+C_{T}\right) Q-C_{2}(E X-E Q)-C_{1}(E Q-E X)
\end{aligned}
$$

\subsection{The Solving of the Coordination Model of Supply Chain}

As the material demand agrees to different distribution laws due to different demand quantities, the total profit of manufacturer, pooling provider and the supply chain during a certain ordering cycle need to be calculated by different means. When the demand quantity $X$ is in accordance with Normal Distribution, the optimal expected profit of pooling provider is got via formula (6):

$$
\begin{gathered}
\mathrm{E}\left(\prod_{I C}\right)=\phi P\left[Q-\int_{0}^{Q} F(X) d X\right]-\left(\omega+C_{0}+C_{T}\right) Q+C_{2} \int_{Q}^{\infty} F(X) d X- \\
C_{1} \int_{0}^{Q} F(X) d X+C_{2} Q-C_{2} \lim _{X \rightarrow \infty} X
\end{gathered}
$$

In the material supply process, the maximum of material demand quantity $X$ is a limited value, whose limit can be determined according to actual supply state, thus the value of $Q$ in formula (12) can be got by the following formula:

$$
\begin{gathered}
\frac{\partial \mathrm{E}\left(\prod_{I C}\right)}{\partial Q}=\phi P(1-F(Q))-\left(\omega+C_{0}+C_{T}\right)-C_{2} F(Q)-C_{1} F(Q)+C_{2} \\
\text { Since } \frac{\partial^{2} \mathrm{E}\left(\prod_{I C}\right)}{\partial Q^{2}}=-\left(\phi P+C_{2}+C_{1}\right) \quad f(Q)<0
\end{gathered}
$$

and provided $\frac{\partial \mathrm{E}\left(\prod_{I C}\right)}{\partial Q}=\phi P(1-F(Q))-\left(\omega+C_{0}+C_{T}\right)-C_{2} F(Q)-C_{1} F(Q)+C_{2}=0$

the optimal ordering quantity $Q_{I}$ of pooling provider $I$ can be got via:

$$
Q_{I}=\mathrm{F}^{-1}\left[\frac{\phi P+C_{2}-\left(\omega+C_{0}+C_{T}\right)}{\phi P+C_{2}+C_{1}}\right]
$$

Similarly, formula (7) and (8) can be converted into: 


$$
\begin{gathered}
\mathrm{E}\left(\Pi_{S C}\right)=(1-\phi) P\left[Q-\int_{0}^{Q} F(X) d X\right]+\left(\omega-C_{S}\right) Q . \\
\mathrm{E}\left(\prod_{T}\right)=P\left[Q-\int_{0}^{Q} F(X) d X\right]-\left(C_{s}+C_{0}+C_{T}\right) Q-C_{2} \int_{Q}^{\infty} X f(X) d X+ \\
C_{2} q \int_{Q}^{\infty} f(X) d X-C_{1} Q \int_{0}^{Q} f(X) d X+C_{1} \int_{0}^{Q} X f(X) d X .
\end{gathered}
$$

According to formula (14), (15), the optimal production quantity $\mathrm{Q}_{S}$ of manufacturer and optimal yield $\mathrm{Q}_{T}$ of supply chain are respectively got by the following formula:

$$
\begin{gathered}
\mathrm{Q}_{S}=\mathrm{F}^{-1}\left[\frac{(1-\phi) P-\left(C_{S}-\omega\right)}{(1-\phi) P}\right] . \\
\mathrm{Q}_{T}=\mathrm{F}^{-1}\left[\frac{P+C_{2}-\left(C_{S}+C_{0}+C_{T}\right)}{P+C_{2}+C_{1}}\right] .
\end{gathered}
$$

When the demand quantity $X$ is in accordance with the discrete variable of Poisson Distribution, considering the stock-out compensation and inventory costs, we simplify formula (9) to get the optimal expected profit of pooling provider via:

$$
\begin{gathered}
\mathrm{E}\left(\prod_{I C}\right)=\phi P\left[Q(1-F(Q))+\sum_{0}^{Q} X P(X)\right]-\left(\omega+C_{0}+C_{T}\right) Q-C_{2} \sum_{Q+1}^{\infty} X P(X)+ \\
C_{2} Q(1-F(Q))-C_{1} Q F(Q)+C_{1} \sum_{0}^{Q} X p(X) .
\end{gathered}
$$

Since the demand quantity $X$ is in accordance with Poisson Distribution, and $X$ is a discrete random variable agreeing with distribution function $P(X)$ and it is a step function, its jump point set is $\left\{a_{n}, n \in N\right\}$ within the demand range of $[0,20]$, the corresponding jump height set is $\left\{p_{n}, n \in N\right\}$, in which $a_{n}, p_{n}$ are integers and $a_{n} \in$ $[0,20]$, we can get the following formula from the Riemman-Stielties integral definition:

$$
Q(1-\mathrm{F}(\mathrm{Q}))+\sum_{0}^{Q} X P(X)=Q(1-\mathrm{F}(\mathrm{Q}))+\int_{0}^{Q} X f(X) d X=Q^{-\mathrm{QF}}(\mathrm{Q})+\int_{0}^{Q} X d F(X)=Q^{-} \int_{0}^{Q} F(X) d X
$$

And formula (18) can be converted into:

$$
\begin{gathered}
\mathrm{E}\left(\prod_{I C}\right)=\phi P\left[Q-\int_{0}^{Q} F(X) d X\right]-\left(\omega+C_{0}+C_{T}\right) Q+C_{2} \int_{Q}^{\infty} F(X) d X- \\
C_{1} \int_{0}^{Q} F(X) d X+C_{2} Q-C_{2} \lim _{X \rightarrow \infty} X .
\end{gathered}
$$

From the above we can get the optimal ordering quantity $\mathrm{Q}_{I}^{\prime}$ of pooling provider when the demand quantity $\mathrm{X}$ is in accordance with Poisson Distribution:

Accordingly formulas

$$
\mathrm{Q}^{\prime}{ }_{I}=\mathrm{Q}_{I}=\mathrm{F}^{-1}\left[\frac{\phi P+C_{2}-\left(\omega+C_{0}+C_{T}\right)}{\phi P+C_{2}+C_{1}}\right] .
$$

(10) and (11) can be converted into:

$$
\begin{gathered}
\mathrm{E}\left(\prod_{S C}\right)=(1-\phi) P\left[Q-\int_{0}^{Q} F(X) d X\right]+\left(\omega-C_{S}\right) Q . \\
\mathrm{E}\left(\prod_{T}\right)=P\left[Q-\int_{0}^{Q} F(X) d X\right]-\left(C_{S}+C_{0}+C_{T}\right) Q+C_{2} \int_{Q}^{\infty} F(X) d X-
\end{gathered}
$$




$$
C_{1} \int_{0}^{Q} F(X) d X+C_{2} Q-C_{2} \lim _{X \rightarrow \infty} X
$$

Thus the optimal production $Q_{S}^{\prime}$ of manufacturer and the optimal yield $Q_{T}^{\prime}$ of supply chain are respectively got via:

$$
\begin{gathered}
Q_{S}^{\prime}=Q_{S}=\mathrm{F}^{-1}\left[\frac{(1-\phi) P-\left(C_{S}-\omega\right)}{(1-\phi) P}\right] . \\
Q_{T}^{\prime}=Q_{T}=\mathrm{F}^{-1}\left[\frac{P+C_{2}-\left(C_{S}+C_{0}+C_{T}\right)}{P+C_{2}+C_{1}}\right] .
\end{gathered}
$$

Thus the following proposition can be got based on the above reasoning and value solving.

Proposition 1: Within the material sharing model, considering the stock-out compensation $C_{2}$ and inventory cost $C_{l}$, no matter the demand for turnover material agrees with Poisson Distribution or Normal Distribution, the optimal production $Q_{S}$ of the manufacturer, the optimal ordering quantity $Q_{I}$ of pooling provider and the optimal yield $Q_{T}$ of supply chain composed of manufacturer and pooling provider can be respectively got via

\subsection{Conditions of Revenue Sharing}

$$
\mathrm{F}^{-1}\left[\frac{(1-\phi) P-\left(C_{S}-\omega\right)}{(1-\phi) P}\right], \mathrm{F}^{-1}\left[\frac{\phi P+C_{2}-\left(\omega+C_{0}+C_{T}\right)}{\phi P+C_{2}+C_{1}}\right] \text { and } \mathrm{F}^{-1}\left[\frac{P+C_{2}-\left(C_{S}+C_{0}+C_{T}\right)}{P+C_{2}+C_{1}}\right] .
$$

\subsubsection{Channel Coordination Condition}

In order to achieve the coordination of material supply chain and the optimal expected profit of the manufacturer, pooling provider and the supply chain, the contract parameter of revenue sharing must be determined, and the conditions of channel coordination and profit distribution must be satisfied. The means of revenue sharing contract to achieve supply chain coordination is to provide a certain collaborative agreement for each node on the supply chain and thus enable the policymakers of each phase to adopt strategies in accordance with the optimal strategy on the supply chain. The contract should make equal the optimal ordering quantity $Q_{I}$ of pooling provider, the optimal production $Q_{S}$ of manufacturer and the optimal yield $Q_{T}$ of the supply chain, i.e. $Q_{I}=Q_{S}=Q_{T}$, to ensure the optimal strategy agreement of each phase and the supply chain. From $Q_{I}=Q_{S}$ or $Q_{S}=Q_{T}$ and formulas (13), (16) and (17) we can get:

$$
\begin{array}{r}
\omega=\frac{1}{P+C_{2}+C_{1}}\left[\left(C_{S}+C_{0}+C_{T}\right)\left(\phi P+C_{2}+C_{1}\right)-\right. \\
\left.\left(P+C_{2}\right)\left(\phi P+C_{2}+C_{1}\right)\right]+\left(\phi P+C_{2}\right)-\left(C_{0}+C_{T}\right) \\
=\frac{1}{P+C_{2}+C_{1}}\left[(1-\phi) P\left(P+C_{2}\right)-\left(C_{S}+C_{0}+C_{T}\right)(1-\phi) P\right]+C_{S}-(1-\phi) P .
\end{array}
$$

From $\omega \geq 0$ and formula (25) we can get:

$$
\begin{gathered}
\phi \geq \frac{\left(P+C_{2}+C_{1}\right)\left(C_{S}+C_{0}+C_{T}-C_{2}\right)-\left(C_{2}+C_{1}\right)\left(C_{S}+C_{0}+C_{T}-P-C_{2}\right)}{P\left(C_{S}+C_{0}+C_{T}+C_{1}\right)} \\
\quad \text { or } \phi \geq \frac{\left(P-C_{S}\right)\left(P+C_{2}+C_{1}\right)-P\left(P+C_{2}-C_{S}-C_{0}-C_{T}\right)}{P\left(C_{S}+C_{0}+C_{T}+C_{1}\right)} .
\end{gathered}
$$




\subsubsection{Profit Distribution Condition}

The expected profit of pooling provider and manufacturer must be more than the one when they independently make decisions, only under this condition will the pooling provider and manufacturer consciously keep the promise made in the revenue sharing contract. Suppose the material sales price of manufacturer in independent decision making is $\omega_{0}$, the optimal ordering quantity of pooling provider is accordingly $Q_{0}$, the optimal expected profit of the pooling provider $\mathrm{E}\left(\Pi_{I 2}^{*}\right)$ is:

In the formula:

$$
\begin{gathered}
\mathrm{E}\left(\Pi_{I 2}^{*}\right)=P\left[Q_{0}\left(1-F\left(Q_{0}\right)\right)+\sum_{0}^{Q_{0}} X P(X)\right]-\left(\omega_{0}+C_{0}+C_{T}\right) Q_{0}-C_{2} \sum_{Q_{0}+1}^{\infty} X P(X)+ \\
C_{2} Q_{0}\left(1-F\left(Q_{0}\right)\right)-C_{1} Q_{0} F\left(Q_{0}\right)+C_{1} \sum_{0}^{Q_{0}} X P(X)
\end{gathered}
$$

The optimal expected profit of manufacturer $\mathrm{E}\left(\prod_{S 2}^{*}\right)$ is:

$$
\mathrm{Q}_{0}=\mathrm{F}^{-1}\left[\frac{P+C_{2}-\left(\omega_{0}+C_{0}+C_{T}\right)}{P+C_{2}+C_{1}}\right] .
$$

$$
\mathrm{E}\left(\prod_{S 2}^{*}\right)=\left(\omega_{0}-C_{S}\right) Q_{0}
$$

In the collaborative decision-making by both manufacturer and pooling provider, we apply $Q_{T}$ to formula (15) and get the optimal expected profit of supply chain as follows:

$$
\begin{gathered}
\mathrm{E}\left(\prod_{T}^{*}\right)=P\left[\mathrm{Q}_{T}\left(1-F\left(\mathrm{Q}_{T}\right)\right)+\sum_{0}^{Q_{T}} X P(X)\right]-\left(C_{0}+C_{S}+C_{T}\right) \mathrm{Q}_{T}-C_{2} \sum_{\mathrm{Q}_{T}+1}^{\infty} X P(X)+ \\
C_{2} \mathrm{Q}_{T}\left(1-F\left(\mathrm{Q}_{T}\right)\right)-C_{1} \mathrm{Q}_{T} F\left(\mathrm{Q}_{T}\right)+C_{1} \sum_{0}^{Q_{T}} X P(X)
\end{gathered}
$$

Apply $Q_{T}$ to formula (12) and formula (14), and we get the optimal expected profit of pooling provider and supplier respectively as follows:

$$
\begin{gathered}
\mathrm{E}\left(\prod_{I C}^{*}\right)=\phi P\left[\mathrm{Q}_{T}\left(1-F\left(\mathrm{Q}_{T}\right)\right)+\sum_{0}^{\mathrm{Q}_{T}} X P(X)\right]-\left(\omega+C_{0}+C_{T}\right) \mathrm{Q}_{T}-C_{2} \sum_{Q_{T}+1}^{\infty} X P(X)+ \\
C_{2} \mathrm{Q}_{T}\left(1-F\left(\mathrm{Q}_{T}\right)\right)-C_{1} \mathrm{Q}_{T} F\left(\mathrm{Q}_{T}\right)+C_{1} \sum_{0}^{Q_{T}} X P(X) \\
\mathrm{E}\left(\prod_{S C}^{*}\right)=(1-\phi) P\left[\mathrm{Q}_{T}\left(1-F\left(\mathrm{Q}_{T}\right)+\sum_{0}^{Q_{T}} X P(X)\right]+\left(\omega-C_{S}\right) \mathrm{Q}_{T} .\right.
\end{gathered}
$$

From formulas (25), (31) and (32) the value of revenue sharing factor $\phi$ is:

$$
\begin{aligned}
& \phi=\frac{1}{P\left[Q_{T}\left(1-F\left(Q_{T}\right)\right)+\sum_{0}^{Q_{T}} X P(X)-\frac{Q_{T}}{P+C_{2}+C_{1}}\left(C_{S}+C_{0}+C_{T}-P-C_{2}\right)-Q_{T}\right]} \\
& \times\left\{E\left(\prod_{I C}^{*}\right)+Q_{T}\left(C_{0}+C_{T}\right)+C_{1}+Q_{T}\left(C_{2}-C_{0}-C_{T}\right)+\frac{Q_{T}}{P+c_{2}+c_{1}}\left(C_{S}+C_{0}+C_{T}-P-C_{2}\right) C_{2}\right. \\
& \quad-\left(-C_{2} \sum_{Q_{T}+1}^{\infty} X P(X)+C_{2} Q_{T}\left(1-F\left(Q_{T}\right)\right)-C_{1} Q_{T} F\left(Q_{T}\right)+C_{1} \sum_{0}^{Q_{T}} X P(X)\right\}
\end{aligned}
$$




$$
\begin{aligned}
\phi= & \frac{1}{P\left[Q_{T}\left(1-F\left(Q_{T}\right)\right)+\sum_{0}^{Q_{T}} X P(X)-\frac{Q_{T}}{P+C_{2}+C_{1}}\left(C_{S}+C_{0}+C_{T}-P-C_{2}\right)-Q_{T}\right]} \\
& \times\left\{P\left[Q_{T}\left(1-F\left(Q_{T}\right)\right)+\sum_{0}^{Q_{T}} X P(X)\right]-\mathrm{E}\left(\prod_{S C}^{*}\right)+\left(C_{2}-C_{0}-C_{T}\right) Q_{T}\right. \\
& \left.+\frac{Q_{T}}{P+C_{2}+C_{1}}\left(C_{S}+C_{0}+C_{T}-P-C_{2}\right) C_{2}-C_{S} Q_{T}+C_{1}\right\}
\end{aligned}
$$

From $E\left(\prod_{I C}^{*}\right) \geq E\left(\prod_{I 2}^{*}\right)$ and $\mathrm{E}\left(\Pi_{s C}^{*}\right) \geq \mathrm{E}\left(\Pi_{S 2}^{*}\right)$ the profit distribution condition met by contract parameter in collaborative decision-making can be got as follows:

$$
\begin{aligned}
& \phi \geq \frac{1}{P\left[Q_{T}\left(1-F\left(Q_{T}\right)\right)+\sum_{0}^{Q_{r}} X P(X)-\frac{Q_{T}}{P+C_{2}+C_{1}}\left(C_{S}+C_{0}+C_{T}-P-C_{2}\right)-Q_{T}\right]} \\
& \times\left\{E\left(\Pi_{I 2}^{*}\right)+Q_{T}\left(C_{0}+C_{T}\right)+\frac{Q_{T}}{P+c_{2}+c_{1}}\left(C_{S}+C_{0}+C_{T}-P-C_{2}\right) C_{2}+C_{1}+Q_{T}\left(C_{2}-C_{0}-C_{T}\right)\right. \\
&\left.\quad-\left(-C_{2} \sum_{Q_{r}+1}^{\infty} X P(X)+C_{2} Q_{T}\left(1-F\left(Q_{T}\right)\right)-C_{1} Q_{T} F\left(Q_{T}\right)+C_{1} \sum_{0}^{Q_{T}} X P(X)\right)\right\} \\
& \phi \leq \\
& P\left[Q_{T}\left(1-F\left(Q_{T}\right)\right)+\sum_{0}^{Q_{T}} X P(X)-\frac{1}{P+C_{2}+C_{1}}\left(C_{S}+C_{0}+C_{T}-P-C_{2}\right)-Q_{T}\right] \\
& \times\left\{P\left[Q_{T}\left(1-F\left(Q_{T}\right)\right)+\sum_{0}^{Q_{T}} X P(X)\right]-\mathrm{E}\left(\Pi_{S 2}^{*}\right)-C_{S} Q_{T}+\left(C_{2}-C_{0}-C_{T}\right) Q_{T}\right. \\
&\left.\quad+\frac{Q_{T}}{P+C_{2}+C_{1}}\left(C_{S}+C_{0}+C_{T}-P-C_{2}\right) C_{2}+C_{1}\right\}
\end{aligned}
$$

From (26), (33) and (34) the value range of $\phi$ is:

$$
\begin{aligned}
& \max \left\{\frac{\left(P+C_{2}+C_{1}\right)\left(C_{S}+C_{0}+C_{T}-C_{2}\right)-\left(C_{2}+C_{1}\right)\left(C_{S}+C_{0}+C_{T}-P-C_{2}\right)}{P\left(C_{S}+C_{0}+C_{T}+C_{1}\right)},\right. \\
& \left.\frac{\mathrm{E}\left(\Pi_{r 2}^{*}\right)+\mathrm{Q}_{T}\left(C_{0}+C_{T}\right)+\frac{\mathrm{Q}_{T}}{P+c_{2}+c_{1}}\left(C_{S}+C_{0}+C_{T}-P-C_{2}\right)\left(C_{2}+C_{1}\right)+\mathrm{Q}_{T}\left(C_{2}-C_{0}-C_{T}\right)-\left(-C_{2} \sum_{Q_{t}+1}^{\infty} X P(X)+C_{2} \mathrm{Q}_{T}\left(1-F\left(\mathrm{Q}_{T}\right)\right)-C_{1} \mathrm{Q}_{T} F\left(\mathrm{Q}_{T}\right)+C_{1} \sum_{0}^{Q_{t}} X P(X)\right)}{P\left[\mathrm{Q}_{T}\left(1-F\left(\mathrm{Q}_{T}\right)\right)+\sum_{0}^{Q_{T}} X P(X)-\frac{\mathrm{Q}_{T}}{P+C_{2}+C_{1}}\left(C_{S}+C_{0}+C_{T}-P-C_{2}\right)-\mathrm{Q}_{T}\right]}\right\} \\
& \leq \phi \leq \frac{P\left[\mathrm{Q}_{T}\left(1-F\left(\mathrm{Q}_{T}\right)\right)+\sum_{0}^{Q_{T}} X P(X)\right]-\mathrm{E}\left(\Pi_{S 2}^{*}\right)-C_{S} \mathrm{Q}_{T}+\frac{\mathrm{Q}_{T}}{P+C_{2}+C_{1}}\left(C_{S}+C_{0}+C_{T}-P-C_{2}\right)\left(C_{2}+C_{1}\right)+\left(C_{2}-C_{0}-C_{T}\right) \mathrm{Q}_{T}}{P\left[\mathrm{Q}_{T}\left(1-F\left(\mathrm{Q}_{T}\right)\right)+\sum_{0}^{Q_{Q}} X P(X)-\frac{\mathrm{Q}_{T}}{P+C_{2}+C_{1}}\left(C_{S}+C_{0}+C_{T}-P-C_{2}\right)-\mathrm{Q}_{T}\right]} .
\end{aligned}
$$

The above contract form is based on managing model of air material sharing. For the supplying model of the materials leased by the airlines, provided the reasonable leasing price is $P$ and the airline offering the leased materials is considered as pooling provider, the above contract applies to the leased material supply model among airlines, and the demand quantity $X$ is the total of the two airlines. From the above, we can get the following propositions:

Proposition 2: On the basis of introducing revenue-sharing contract, pooling provider can derive more expected profit, with stock-out compensation $C_{2}$ and inventory $\operatorname{cost} C_{1}$ considered, by choosing reasonable revenue sharing factor while coordinating the material supply chain.

The value of revenue share $\phi$ is variable within a certain range, when $\phi$ is beyond the range and equals 0 , and $\omega=P$, it can be considered a supply chain model of pure inventory management, then $\omega$ is a pure ordering price, $\omega$ must be more than the cost price $C_{S}$. This model applies to the supply model of self-ordering storage of airlines and military aviation sectors, and the ordering quantity is determined by the quantity at the time of independent decision-making of pooling provider and manufacturer. 


\section{The Collaborative Decision-Making Algorithm and Application Analysis}

\subsection{Collaborative Decision-Making Algorithm for Manufacturer and Pooling Provider}

In the material supply chain network composed of manufacturer and pooling provider, the chain can be coordinated and optimized, the optimal production and expected profit of manufacturer, pooling provider and supply chain can be achieved by means of introducing revenue-sharing contract mechanism into air material supply process, designing proper revenue-sharing contract form and parameter and coordinating and optimizing the supply chain. Since the manufacturer and the pooling provider are at different nodes of the information network of supply chain, in the course of supply chain coordination, it is necessary for them to exchange the decision-making information such as the sharing price $P$, the unit operational $\operatorname{cost} C_{S}$ and the unit transportation $\operatorname{cost} C_{T}$ of manufacturer, the unit operational $\operatorname{cost} C_{0}$, unit inventory cost $C_{1}$, unit $\operatorname{cost} C_{2}$ of missing piece cost of pooling provider and to coordinate the decision making goals such as sales price $\omega$ and profit distribution parameter $\phi$ of manufacturer. In this way the optimization of supply chain can be achieved and the collaborative decision can be made. The calculation steps of collaborative decision-making are as follows:

Step 1: The manufacturer and pooling provider exchange the decision-making information such as sharing price $P$ and operational cost $C_{S}$ and $C_{0}$, and meanwhile initiate the data such as model parameters and termination conditions.

Step 2: According to formula (17) and (28), the manufacturer and pooling provider respectively calculate the ordering quantity $Q_{T}$ within the model of collaborative decision-making and the ordering quantity $Q_{0}$ when making decisions independently. According to (27), (29) and (30) we respectively get the expected profit $\mathrm{E}\left(\prod_{T}^{*}\right)$ of the supply chain within the model of collaborative decision-making, the expected profit $\mathrm{E}\left(\prod_{I 2}^{*}\right)$ of the pooling provider when making decisions independently, the expected profit $\mathrm{E}\left(\Pi_{S 2}^{*}\right)$ of the manufacturer when making decisions independently. According to formula (35), we can get the value range of revenue distribution proposition $\phi$ between pooling provider and manufacturer while collaboratively making decisions.

Step 3: The manufacturer and pooling provider determine the value of revenue distribution proportion $\phi$ according to their own value standard, then according to formulas (25), (31) and (32) respectively get the production price, the profit $\mathrm{E}\left(\Pi_{I C}^{*}\right)$ of pooling provider and the profit $\mathrm{E}\left(\Pi_{S C}^{*}\right)$ of manufacturer and then pass on the value $\phi$ to the other party.

Step 4: The manufacturer and pooling provider respectively get production price $\omega^{\prime}$, the profit $\mathrm{E}\left(\prod_{I C}^{*}\right)^{\prime}$ of pooling provider and the profit $\mathrm{E}\left(\prod_{S C}^{*}\right)^{\prime}$ of manufacturer according to the value of $\phi$ passed on by the other party and formulas (25), (31) and (32). If $\mathrm{E}\left(\prod_{I C}^{*}\right)^{\prime} \geq \mathrm{E}\left(\Pi_{I C}^{*}\right), \mathrm{E}\left(\Pi_{S C}^{*}\right)^{\prime} \geq \mathrm{E}\left(\Pi_{S C}^{*}\right)$, they reach step 5 . Otherwise, they determine the value of $\phi$ and pass on a certain collaborative condition to the other party and reach step 3 .

Step 5 They terminate the process of collaborative decision-making, get the optimal production plan $Q$ in the supply chain, the profit distribution parameter $\phi$, production price $\omega$ and the optimal expected profit $\mathrm{E}\left(\Pi_{T}\right)$ of the supply chain.

\subsection{Application Analysis}

Suppose the demand quantity $X$ of a certain material of pooling provider is in accordance with Poisson Distribution in which $\lambda$ is 13 , and $P=19,000, \omega_{0}=9000, C_{S}=8,100, C_{0}=1,200, C_{T}=500, C_{I}=9,000 * 0.24=2,160$, $C_{2}=91,000$, then according to formulas (17) and (28), the ordering quantity $Q_{T}$ is 16 within the model of collaborative decision-making and the ordering quantity $Q_{0}$ of pooling provider and manufacturer when making decisions independently is 15 . From formulas (27), (29) and (30), the profit $\mathrm{E}\left(\prod_{I 2}^{*}\right)$ of pooling 
provider when making decisions independently is 8,978 , the profit $\mathrm{E}\left(\prod_{S 2}^{*}\right)$ of manufacturer when making decisions independently is 13,500 , the profit $\mathrm{E}\left(\Pi_{T}^{*}\right)$ of the supply chain when making decisions collaboratively is 22,800 . From formula (35) we can get the value range of revenue distribution proportion $\phi$ between pooling provider and manufacturer as $0.9203 \leq \phi \leq 0.9222$. From formulas (25), (31) and (32) we can get the production price $\omega$, the profit $\mathrm{E}\left(\prod_{I C}^{*}\right)$ of pooling provider and the profit $\mathrm{E}\left(\prod_{S C}^{*}\right)$ of manufacturer with different values of $\phi$, illustrated by Table 1 .

Table 1. The profit of pooling provider and manufacturer

\begin{tabular}{lcccc}
\hline Revenue-sharing contract & & \multicolumn{2}{c}{ Total expected profit distribution under different } \\
contracts
\end{tabular}

Since pooling provider and manufacturer can now both get higher profit within the value range of $\phi$ than that when making decisions independently and the profit fluctuates with the change of $\phi$ value, suppose $Y_{i}$ is now the expected profit of pooling provider while $Y_{s}$ the expected profit of manufacturer, then with the revenue share $\phi$ changing, the expected profit of pooling provider and manufacturer changes as figure 1 .

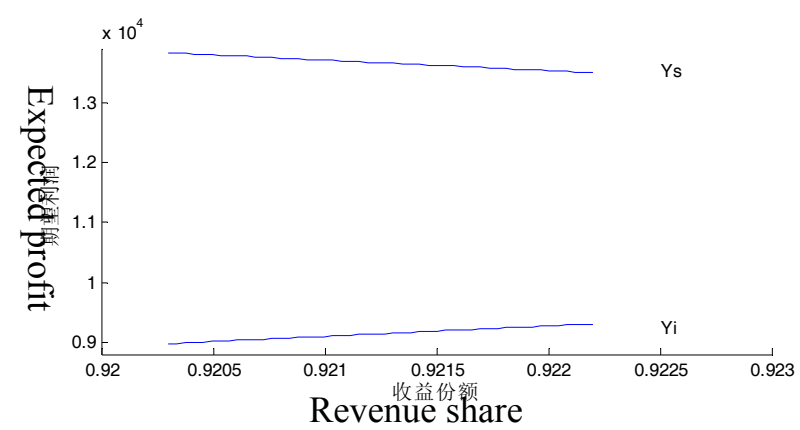

Figure 1. The revenue change of pooling provider and manufacturer with the variation of revenue share

The figure shows that the expected profit of pooling provider monotonically increases with the rise of revenue share and the expected profit of manufacturer monotonically decreases with the rise of revenue share. Therefore, in the course of collaborative decision-making, pooling provider and manufacturer both tend to choose a bigger revenue share so as to maximize its own expected profit. In the actual course of decision making, according to the different positions of the two parties, the leading one can determine a value standard based on the negotiation result so as to get the value of $\phi$, the revenue distribution proportion. Generally, the value of $\phi$ is 0.92125 by means of mean method, then the production price and the optimal expected profit of pooling provider and manufacturer are respectively 7940.4, 9142.1 and 13658.

\section{Conclusion}

This paper by means of analyzing the model of air material demand and supply studies the method of introducing revenue-sharing contract into air material supply process considering stock-out compensation and inventory cost. It establishes the two-level coordinating model of supply chain made up of manufacturer and pooling provider within the model of air material sharing. It by means of designing proper contract form and contract parameters presents the reasonable expected profit of the supply chain distributed between the pooling provider and manufacturer. It then optimizes the entire state of air material supply process, the production of each node and ordering storage state so as to achieve optimization of the collaborative decision making of air material supply and the performance of supply chain. The research shows that the expected profit of pooling provider and manufacturers varies with the change of revenue share, but within a certain range of revenue share, 
supply chain coordination can be achieved, and no matter which node on the supply chain leads, the chain members can for more profit attract other members to join in the supply chain coordination by means of regulating revenue share in order to optimize the collaborative decision-making of supply chain and expected profit.

\section{References}

Adel, A. G., \& Chris, H. F. (2003). Evaluation of forecasting methods for intermittent parts demand in the field of aviation: a predictive model. Computers \& Operations Research, 30(14), 2097-2114. http://dx.doi.org/10.1016/S0305-0548(02)00125-9

Cachon, G. P., \& Lariviere, M. A. (2005). Supply chain coordination with revenue-sharing contracts: Strengths and limitations. Management Science, 51(1), 30-44. http://dx.doi.org/10.1287/mnsc.1040.0215

Cai, J. H., Han, Y., \& Huang, Z. Q. (2011). Coordination Mechanism and Revenue-Sharing Contract Design Considering Customers' Strategic Behavior. Journal of Shanghai Jiaotong University, 45(12), 1765-1771.

Chen, J., \& Zhang, N. (2008). Study on backorder incentives and inventory control policies with time-based customer-choice behavior. Journal of Management Sciences in China, 11(3), 53-62.

Ghobbar, A. A., \& Friend, C. H. (2002). Sources of intermittent demand for aircraft spare parts within airline operations. Journal of Air Transport Management, 8(4), 221-231. http://dx.doi.org/10.1016/S0969-6997(01)00054-0

Hugo, S., \& Warren, P. (2009). Approximate dynamic programming for management of high-value spare parts. Journal of Manufacturing Technology Management, 20(2), 147-160. http://dx.doi.org/10.1108/17410380910929592

Jani, K., Ari, P. J., \& Vepsäläinen. (2004). Pooling of spare components between airlines. Journal of Air Transport Management, 10(2), 137-146. http://dx.doi.org/10.1016/j.jairtraman.2003.09.001

Jani, K., Juuso, T., \& Ari, V. (2009). Cooperative strategies for the availability service of repairable aircraft components. International Journal of Production Economics, 117(2), 360-370. http://dx.doi.org/10.1016/j.ijpe.2008.12.001

Jeffery, K. C., \& Theodore, P. L. (2002). Computing small-fleet aircraft availabilities including redundancy and $\begin{array}{lllll}\text { spares. } \quad \text { Computers } \& \text { Operations } & \text { 29(5), }\end{array}$ http://dx.doi.org/10.1016/S0305-0548(00)00094-0

Kyung, B. Y., \& So, Y. S. (2007). Finding the optimal CSP inventory level for multi-echelon system in Air Force using random effects regression model. European Journal of Operational Research, 180(3), 1076-1085. http://dx.doi.org/10.1016/j.ejor.2006.05.006

Lee, L. H., Chew, E. P., \& Teng, S. (2008). Multi-objective simulation-based evolutionary algorithm for an aircraft spare parts allocation problem. European Journal of Operational Research, 189(2), 476-491. http://dx.doi.org/10.1016/j.ejor.2007.05.036

Munson, C. L., Hu, J. (2010). Incorporating quantity discounts and their inventory impacts into the centralized purchasing decision. European Journal of Operational Research, 201(2), 581-592. http://dx.doi.org/10.1016/j.ejor.2009.03.043

Regattieri, A., Gamberi, M., \& Gamberini, R. (2005). Managing lumpy demand for aircraft spare parts. Journal of Air Transport Management, 11(6), 426-431. http://dx.doi.org/10.1016/j.jairtraman.2005.06.003

Selcuk, K., \& Ismail, S. B. (2013). Joint quantity flexibility for multiple products in a decentralized supply chain. Computers \& Industrial Engineering, 64(2), 696-707. http://dx.doi.org/10.1016/j.cie.2012.12.004

Wan, Y. C., He, Y. Q., \& Sheng, Z. H. (2004). Generalized Weighted Functional Proportional Mean Combining Forecasting Model of Air Material Consumption. Acta Automatica Sinica, 30(4), 619-623.

Wong, W. K., Qi, J., \& Leung, S. Y. S. (2009). Coordinating supply chains with sales rebate contracts and vendor-managed inventory. International Journal of Production Economics, 120(1), 151-161. http://dx.doi.org/10.1016/j.ijpe.2008.07.025

Xiong, H. C., Chen, B. T., \& Xie, J. X. (2011). A composite contract based on buy back and quantity flexibility contracts. European Journal of Operational Research, 210(3), 559-567. http://dx.doi.org/10.1016/j.ejor.2010.10.010

Xu, N. X., \& Linda, N. (2009). Modeling supplier selection and the use of option contracts for global supply 
chain design. Computers \& Operations Research, 36(10), 2786-2800. http://dx.doi.org/10.1016/j.cor.2008.12.013

\section{Copyrights}

Copyright for this article is retained by the author(s), with first publication rights granted to the journal.

This is an open-access article distributed under the terms and conditions of the Creative Commons Attribution license (http://creativecommons.org/licenses/by/3.0/). 